\title{
Surface acid-base properties and hydration/dehydration mechanisms of aluminum (hydr)oxides
}

\author{
Xiaofang Yang a , Zhongxi Sun ${ }^{\mathrm{b}, *}$, Dongsheng Wang ${ }^{\mathrm{a}}$, Willis Forsling ${ }^{\mathrm{c}}$

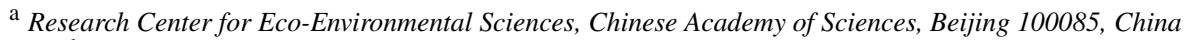 \\ ${ }^{\mathrm{b}}$ Department of Chemistry and Chemical Engineering, Jinan University, Jinan 250022, China \\ ${ }^{c}$ Division of Chemistry, Department of Chemical Engineering and Geosciences, Luleå University of Technology, SE-97 187 Luleå, Sweden
}

Received 10 October 2006; accepted 6 December 2006

Available online 31 January 2007

\begin{abstract}
In this paper, surface physiochemical properties of three typical aluminas, $\gamma$ - $\mathrm{Al}(\mathrm{OH})_{3}, \gamma-\mathrm{Al}_{2} \mathrm{O}_{3}$, and $\alpha$ - $\mathrm{Al}_{2} \mathrm{O}_{3}$, were investigated by means of XRD, SEM, TEM, BET surface area, TG/DTA, and potentiometric titration techniques. Based on the titration data, surface protonation and deprotonation constants were determined using the constant capacitance model (CCM). The emphasis of this research was laid on the comparison of the crystal structure, surface hydration/dehydration and acid-base properties of these three typical alumina minerals. The calculation results revealed that the surface acidity of the aluminas is in the order of $\alpha-\mathrm{Al}_{2} \mathrm{O}_{3}>\gamma-\mathrm{Al}(\mathrm{OH})_{3}>\gamma-\mathrm{Al}_{2} \mathrm{O}_{3}$ after being hydrated for $1 \mathrm{~h}$. The correlation between the hydration/dehydration mechanisms of alumina and its acid/base properties is discussed.
\end{abstract}

(c) 2006 Elsevier Inc. All rights reserved.

Keywords: Acid-base properties; Aluminum (hydr)oxides; Surface hydration; Crystal structure

\section{Introduction}

Aluminum (hydr)oxides as the most common minerals in soils and aquatic environments are widely used as adsorbents and catalysts in industrial processes [1,2]. The physicochemical reactions at the surface of aluminum (hydr)oxides are complicated largely due to the hydration kinetics, phase transformation, and impurity inclusions, as well as mineral dissolution. Deep knowledge of alumina surface reactions is greatly needed to understand the mechanisms involved in the aforementioned phenomena in order to improve and optimize relevant industrial processes.

It is well established that many mineral-aqueous interface processes heavily depend on the nature and structure of surface sites [3,4]. On the hydroxylated surface of aluminum oxides, the surface hydroxyl groups may ionize as Brønsted acid or base sites in appropriate circumstances. The nature of surface sites determines the ability to bind protons, and then the con-

\footnotetext{
* Corresponding author. Fax: +86 053187161600.

E-mail address: sunzx@ujn.edu.cn (Z. Sun).
}

centration of these sites macroscopically presents acid-base properties $[5,6]$. The surface charge, which is due to the protonation/deprotonation reaction of surface sites, is mainly a function of $\mathrm{pH}$ and the ionic strength of the aqueous solution, and consequently potentiometric titration techniques are the most commonly used method to evaluate the surface acid-base properties [7-11]. However, due to the slow surface hydration process, phase transformations at the surface and the solubility of oxides $[4,7,12-15]$, the titration results should be carefully evaluated in order to obtain consistent interpretation of various macroscopic parameters, such as PZC values and the acidity constants.

To understand and describe the surface reactions at the solid-liquid interface, a variety of surface reaction models have been proposed [16-25]. Most of these models involve interface reactions at fixed surface sites, including different electrostatic layers, besides surface protonation or deprotonation.

In the original view of the classical $2 \mathrm{p} K$ model the surface binding sites include a neutral "ground stated" site (SOH), which could be protonated or deprotonated with equilibrium constants $K$ [5]. The combination of the $2 \mathrm{p} K$ model with the electrostatic double-layer model has been used extensively in 
the field of surface complexation research $[3,7,8,10,20-22]$. In the last two decades, Bolt and Riemsdijk [23] proposed the use of solely one $\mathrm{p} K$ value for the $\mathrm{Al}$ and $\mathrm{Fe}$ hydroxides. In the $2 \mathrm{p} K$ and $1 \mathrm{p} K$ models, the active sites are supposed to be distributed randomly at the surface; i.e., the surface was assumed to be chemically homogeneous. However, crystallographic and spectroscopic studies $[2,26]$ identified different types of hydroxyl entities existing at the surface. Thus Hiemstra et al. $[24,25]$ proposed a charge distribution multisite complexation (CD-MUSIC) model to describe the surface complexation behavior of crystal oxides. However, due to the complexity to determine the surface sites ratio, it is difficult to correlate the experimental data at different faces and to perform theoretical MUSIC calculations.

The development of surface reaction models indicated that the correlation between the crystal structure, morphology and surface chemistry was incorporated. The surface structure, which is basically related to the crystal structure, determines the relation between the $\mathrm{Al}$ ions and the surface oxygens that correspond to the different types of surface sites. The crystal morphology determines the distribution of crystal cleavage planes and consequently the surface structure and morphology directly affect the surface acid-base properties. However, due to the influence of the water layer immediately adjacent to the solid surface, the surface structure may be inconsistent to the bulk crystal structure. Nevertheless, since the type and number of surface hydroxyl groups depend on the crystal planes that are preferentially exposed, as well as how metal ions are distributed at the surface [27], the properties are related to the crystal structure and morphology, i.e., the nature of the (hydr)oxide particles. Moreover, considering the morphological shapes, sizes, composition, and crystallinity of oxides, possibly depend on the history of samples, the reported surface parameters in past decades are spread over a wide range and might not be directly comparable. For instance, in the literature, the PZC (point of zero charge) values of gibbsite vary between 8.7 and 10.0 , and 6.45 to 9.2 for $\gamma-\mathrm{Al}_{2} \mathrm{O}_{3}$, while the values of the specific surface area vary between 8 and $30 \mathrm{~m}^{2} / \mathrm{g}$ (BET) for gibbsite [9,15,28-30].

Furthermore, it is well known that the hydrated alumina surfaces pass through phase transformations during the hydration process. The surface morphologies keep changing during the hydration process. For instance, the surface of $\gamma-\mathrm{Al}_{2} \mathrm{O}_{3}$ transforms to bayerite with prolonged hydration [12-14] and a mixture of $\alpha-\mathrm{Al}(\mathrm{OH})_{3}$ (bayerite) and $\gamma-\mathrm{Al}(\mathrm{OH})_{3}$ (gibbsite) appears when the surface of $\alpha-\mathrm{Al}_{2} \mathrm{O}_{3}$ is exposed to water vapor for an hour [31]. Due to the chemical transformations and the complexity of the surface morphology during the hydration process of alumina, we can understand the aforementioned variation of surface properties. The comparison of the surface properties of various alumina minerals can only be justified using the same time of hydration and the surfaces of different aluminas tend to be more similar at increased hydration times. We may get some insight by comparing the relation between the structure and properties of different types of alumina at the same limited time of hydration.
The aim of our research is to explore the relation between the structure and surface properties of three typical aluminum (hydr)oxides with different crystal structure, i.e., gibbsite, $\gamma$-alumina, and $\alpha$-alumina, under the condition of the same hydration period. To avoid possible morphological changes at the alumina surfaces during hydration, $1 \mathrm{~h}$ hydration time was chosen for all potentiometric titration experiments in our studies.

\section{Experimental}

\subsection{Materials}

Three typical aluminum (hydr)oxides with different crystal structure, i.e., gibbsite, $\gamma$-alumina, and $\alpha$-alumina, were investigated. Sample A (gibbsite) and sample C ( $\alpha$-alumina) are commercial aluminum (hydr)oxide products, and sample B ( $\gamma$-alumina) is obtained by heating sample $\mathrm{A}$ at $550^{\circ} \mathrm{C}$ for $1.5 \mathrm{~h}$. Their crystal structures were confirmed by $\mathrm{X}$-ray powder diffraction to be predominantly gibbsite, $\alpha$-alumina, and semicrystalline $\gamma$-alumina, respectively.

All solutions were prepared using deionized distilling water and all chemicals used in experiments were guaranteed reagent grade.

\subsection{Sample characterization}

The specific surface areas of three aluminum oxide samples were measured by the $\mathrm{N}_{2} / \mathrm{BET}$ method. $\mathrm{N}_{2}$ adsorption/ desorption isotherms were obtained at $77 \mathrm{~K}$ on a Quantachrome NOVA 2000e surface and pore size analyzer using a static adsorption procedure. Samples were degassed at $150^{\circ} \mathrm{C}$ in a vacuum below $10^{-3}$ Torr for $16 \mathrm{~h}$ before the BET specific surface area measurement. The specific surface area of the sample was calculated using the BET equation, in the $\mathrm{N}_{2}$ relative pressures $P / P_{0}$ range between 0.05 and 0.3 .

Thermal gravimetry (TG) and differential thermal analysis (DTA) measurements of gibbsite were performed using a Perkin-Elmer TG/DTA instrument (PE Diamond) for sample $\mathrm{A}$ in the temperature range of 16 to $1270^{\circ} \mathrm{C}$ under a flow of dry nitrogen. The temperature scanning rate was $10^{\circ} \mathrm{C} / \mathrm{min}$.

The sample morphology and particle shapes were observed by scanning electron microscopy (SEM) and transmission electron microscope (TEM) (Hitachi). The particle size distribution in mineral suspension was determined by particle size analyzer (Malvern, Mastersizer 2000).

The solubility of samples A, B, and C was determined by batch experiments. Alumina suspensions with the same composition as in the acid-base titrations were prepared. The suspension $\mathrm{pH}$ between 3 and 10 was adjusted by adding $\mathrm{HNO}_{3}$ or $\mathrm{KOH}$ to reach the given value. After equilibration $(1$ and $5 \mathrm{~h})$ at various fixed $\mathrm{pH}$ values, the aluminum concentrations in the supernatant solutions were measured by the ICP-OES method.

\subsection{Potentiometric titrations}

The pH-dependent surface charge characteristics of the samples were determined from acid-base titrations. The continu- 


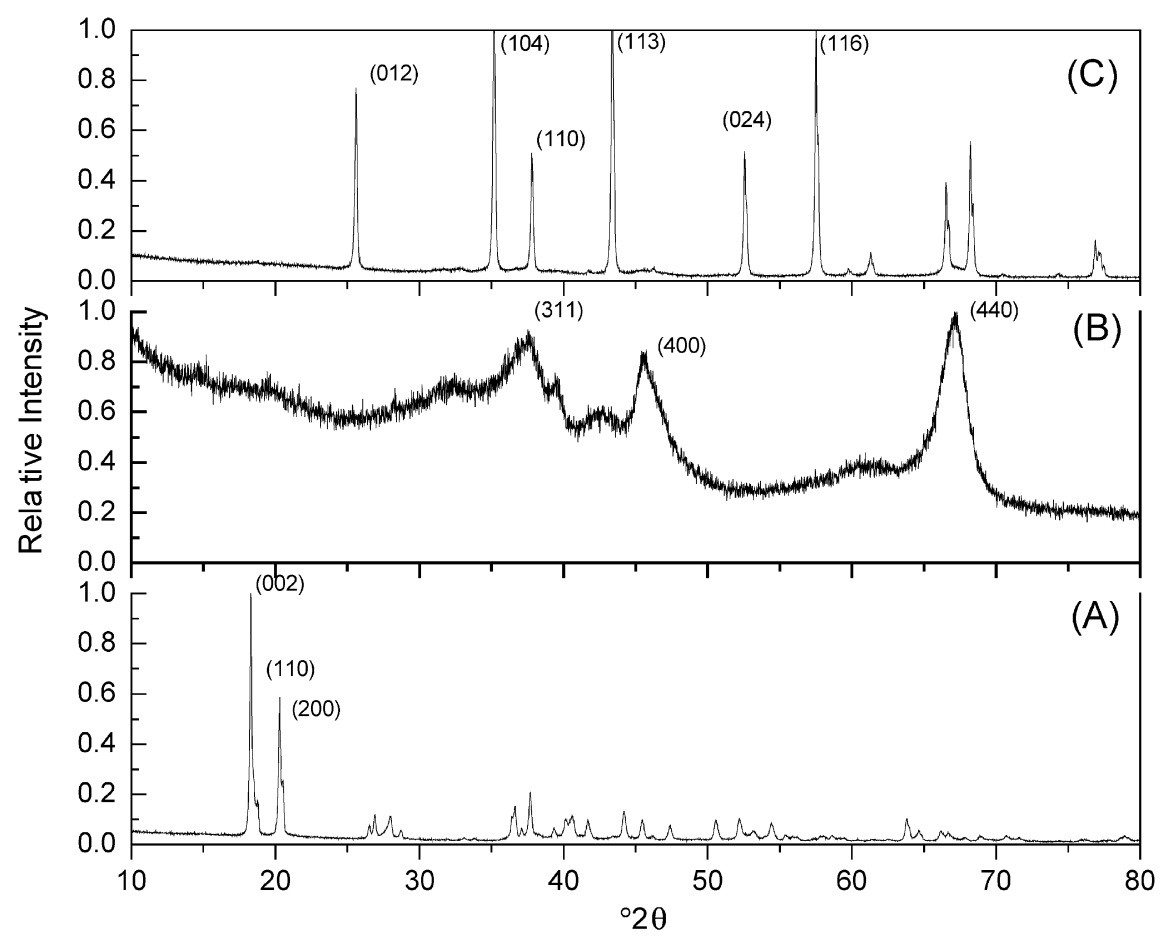

Fig. 1. XRD diagrams of three typical alumina samples.

ous potentiometric titrations were performed under $\mathrm{CO}_{2}$-free conditions using a $\mathrm{KNO}_{3}$ background electrolyte at different ionic strengths $(0.1,0.01$, and $0.001 \mathrm{M}$, respectively). The titrations were carried out at a constant temperature of $25^{\circ} \mathrm{C}$, which was maintained by immersing the titration vessel in a water bath thermostat. The experiments were carried out using a Metrohm automatic system (716 DMS), with a combination $\mathrm{pH}$ electrode calibrated in standard buffer solutions to check the $\mathrm{pH}$ response. Before the titrations started the solid samples were equilibrated in electrolyte solutions for an hour, gently stirred under a continuous stream of purified nitrogen gas. Then the acid or base $\left(\mathrm{HNO}_{3}\right.$ or $\left.\mathrm{KOH}\right)$ was added to the suspension using the DET program method (dynamic equivalence point-titration). The reference electrolyte solution titrations were used to determine the proton activity vs concentration relationship.

Two different titration procedures were performed. In the first procedure the suspension was titrated with acid from the original $\mathrm{pH}$ down to $\mathrm{pH} 4$ and then titrated back to $\mathrm{pH} 10$ with base. In the second one the suspension was titrated with base from the original $\mathrm{pH}$ to $\mathrm{pH} 10$ and then titrated back down to $\mathrm{pH} 3$ with acid. The procedures are presented as $\mathrm{T}$ (two-side titration), BBT (base back-titration), and ABT (acid back-titration), respectively.

\subsection{Modeling calculation}

The titration data were optimized with the $2 \mathrm{p} K$ constant capacitance model (CCM) using a numerical data-fitting program FITEQL 4.0 [32] to determine the intrinsic surface proton affinity constant $\left(\mathrm{p} K_{\mathrm{a} 1}^{\mathrm{int}}, \mathrm{p} K_{\mathrm{a} 2}^{\mathrm{int}}\right)$.

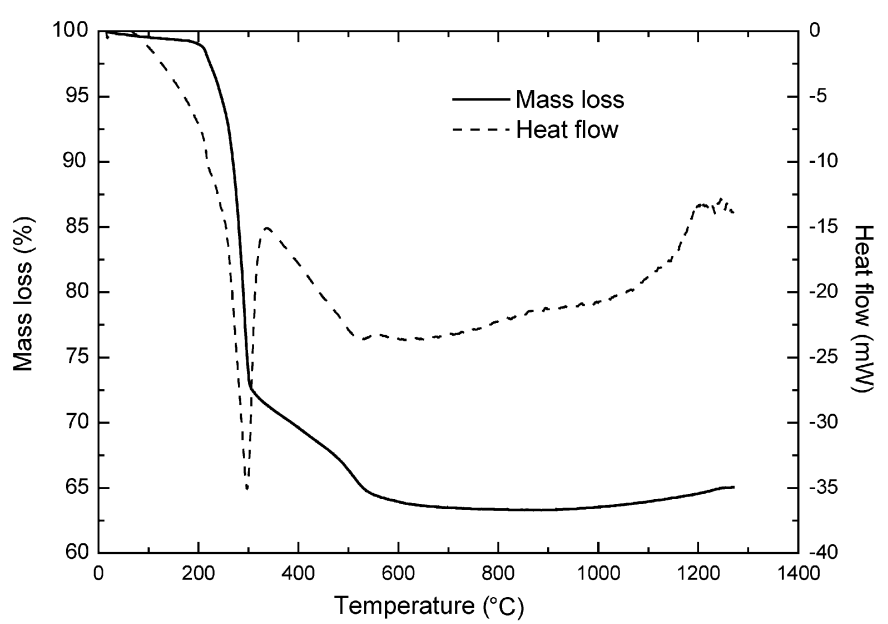

Fig. 2. TG/DTA curves of gibbsite (sample A).

\section{Results and discussion}

The results of the X-ray diffraction measurements indicated that the three samples represented three different common aluminum (hydr)oxide structures, as shown in Fig. 1. In sample A, the predominant phase was found to be gibbsite with a little bayerite phase. Sample B was a sort of transition alumina [33], mainly semicrystalline $\gamma$-alumina phase. Sample $C$ was wellcrystallized $\alpha$-alumina structure.

The TG/DTA analysis of sample A is shown in Fig. 2. The curves can be divided into several regions. From room temperature to $210^{\circ} \mathrm{C}$, both TG and DTA are changing, indicating the release of free bound water. From 210 to about $295^{\circ} \mathrm{C}$, both TG and DTA change dramatically, indicating the release of crystal water $[34,35]$. In this temperature region, the mass loss of 

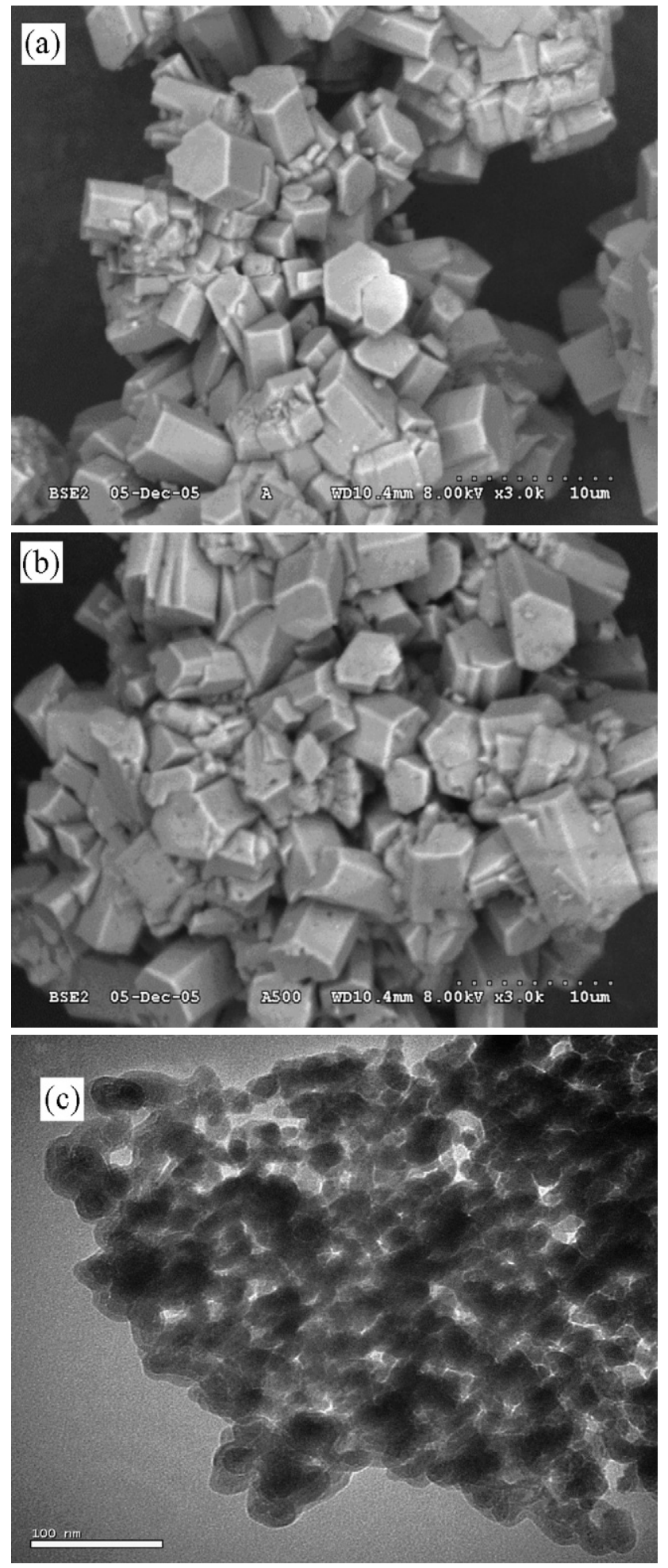

Fig. 3. SEM images for samples: (a) sample A (gibbsite), (b) sample B ( $\gamma$-alumina), and TEM image for (c) sample $\mathrm{C}$ ( $\alpha$-alumina).

the specimen was about $23 \%$, corresponding to the release of two crystal waters and meanwhile a strong endothermic peak appears on the DTA curve. A strong exothermic DTA peak at around $340^{\circ} \mathrm{C}$ possibly indicates the formation of boehmite. The water-releasing process continues, albeit much less dramatically, until about $530^{\circ} \mathrm{C}$, at which all crystal water is released
Table 1

Physicochemical parameters for samples

\begin{tabular}{llll}
\hline & Sample A & Sample B & Sample C \\
\hline Compound name & Gibbsite & $\gamma$-alumina & $\alpha$-alumina \\
Crystal structure & $\gamma$ - $\mathrm{Al}(\mathrm{OH})_{3}$ & $\gamma$-alumina & $\alpha$ - $\mathrm{Al}_{2} \mathrm{O}_{3}$ \\
$\begin{array}{l}\text { Chemical formula } \\
\text { Average crystallite }\end{array}$ & $\mathrm{Al}_{2} \mathrm{O}_{3} \cdot 3 \mathrm{H}_{2} \mathrm{O}$ & $\mathrm{Al}_{2} \mathrm{O}_{3}$ & $\mathrm{Al}_{2} \mathrm{O}_{3}$ \\
$\begin{array}{l}\text { size }(\mathrm{nm}) \\
\text { BET-SSA }\left(\mathrm{m}^{2} / \mathrm{g}\right)\end{array}$ & 226.8 & 9.5 & 190.7 \\
\hline
\end{tabular}

and the mass loss process almost stops. A weak exothermal peak on the DTA curve can be seen at about $550{ }^{\circ} \mathrm{C}$, which may indicate the phase transformation to $\gamma$-alumina. The TG curve then displays a plateau from $530^{\circ} \mathrm{C}$, which indicates that a stable transition phase is formed after dehydration. From 550 to about $1100^{\circ} \mathrm{C}$, there are slight changes of the DTA curve, which may originate from a phase transformation between the aluminas. When the temperature is higher than $1100^{\circ} \mathrm{C}$, the phase transformation of $\alpha$-alumina takes place, which can be observed from the exothermic peak in DTA curve.

The SEM images of sample A and its calcined product (sample B) (Figs. 3a and 3b) indicate that the particles of both samples appeared as hexagonal crystals and existed as agglomerates. The average diameter of a single crystal was about $5 \mu \mathrm{m}$ and the particle size distribution was similar for the two samples. From Fig. 3b, it clearly showed a development of the porosity at the crystal surface. This difference was expected with respect to the specific surface area values, i.e., after heating the specific surface area increased by surface porous texture. In the present study, the dehydration of gibbsite crystals produced $\gamma$-alumina that is pseudomorphic; i.e., the external shape of the gibbsite crystal is retained, but the product exhibits a porous texture.

Sample C was a superfine powder; the TEM image shows aggregates of small particles in nanoscale. From the XRD pattern, the crystalline size is about $191 \mathrm{~nm}$, and the second particles, diameter is about $1.9 \mu \mathrm{m}$.

The external specific surface areas of three samples (A, B, and $\mathrm{C}$ ), as measured by the BET/ $\mathrm{N}_{2}$ method, were $9.97,25.98$, and $29.79 \mathrm{~m}^{2} / \mathrm{g}$, respectively. All results are summarized in Table 1 .

Gibbsite $\left(\gamma-\mathrm{Al}(\mathrm{OH})_{3}\right)$ is one of the main polymorphs of aluminum hydroxides, where the $\mathrm{Al}$ ions are coordinated with six hydroxyls and each hydroxyl is shared with two $\mathrm{Al}$ ions. The crystal growth occurs by extension in the plane of the layer structure ( $a$ and $b$ directions) and by vertical stacking of these layers ( $c$ direction) [36]. This results in the presence of different types of coordinated hydroxyls with different proton affinities and site densities [24,25].

The dehydration of aluminum hydroxides would produce crystalline aluminum oxides. Apart from $\alpha-\mathrm{Al}_{2} \mathrm{O}_{3}$, another six transition crystal structures occur: $\gamma-, \kappa-, \theta-, \eta-, \delta-$, and $\chi-\mathrm{Al}_{2} \mathrm{O}_{3}$ [33]. All these structures are based on a more or less close-packed oxygen lattice with aluminum ions in the octahedral and/or tetrahedral interstices. In the industry, these different types of aluminas, especially $\gamma$-alumina, are often applied as adsorbent and catalyst [2]. However, their structures and 


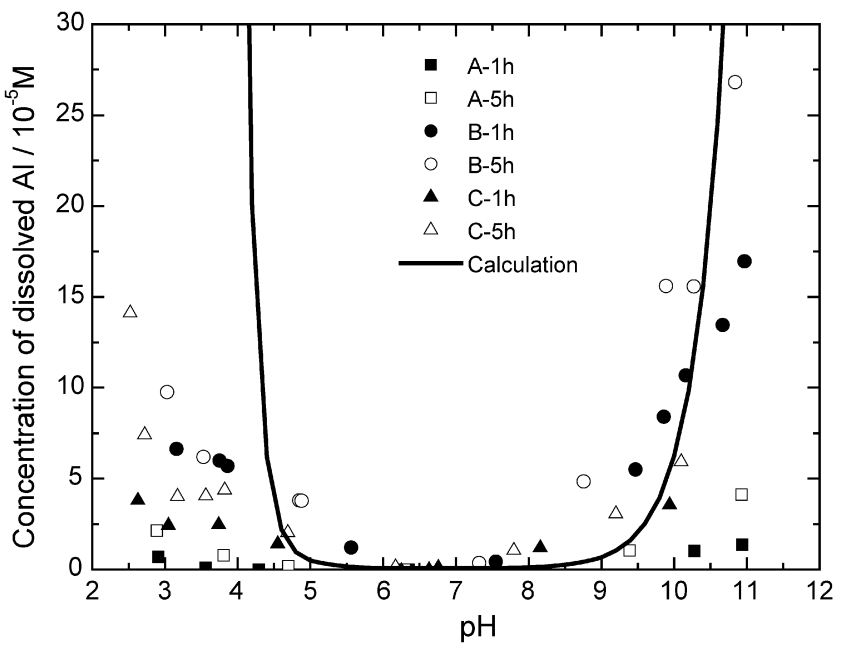

Fig. 4. Total concentration of dissolved aluminum experimental batch values of samples $\mathrm{A}, \mathrm{B}$, and $\mathrm{C}$ for 1 and $5 \mathrm{~h}$ of contact. The line curve was calculated from the solubility product constant of Gibbsite $\left(\mathrm{p} K_{\mathrm{So}}=8.79\right)$ [39].

chemical surface compositions are still not well understood. While the major view is that the $\gamma$-alumina has a defect spinel structure, there have been reports that the $\mathrm{Al}_{2} \mathrm{O}_{3} \cdot n \mathrm{H}_{2} \mathrm{O}(0<$ $n<\sim 0.6)$ form for transition alumina [37]. The $\alpha$-alumina is the end-structure of transition aluminas formed at high temperature, usually known as "corundum," which exists in nature. The $\alpha$-alumina surface in vacuum is generally agreed to be Alterminated [38]. In the bulk structure of $\alpha$-alumina, the $\mathrm{Al}$ ions occupy two-thirds of the octahedral close-packed oxygen ions interstices; but when the surface interacts with water, a surface phase transformation occurs and the fully hydrated surface is oxygen-terminated, i.e., the surface structure seems turned to between $\alpha-\mathrm{Al}_{2} \mathrm{O}_{3}$ and $\mathrm{Al}(\mathrm{OH})_{3}$ phases [31].

Calculation of the surface charge was performed directly from the measured $\mathrm{pH}$ and acid or base added at each data point [3]. The surface excess amount of charge, $Q_{\mathrm{H}}(\mathrm{mol} / \mathrm{L})$, can then be calculated at each titration point as

$Q_{\mathrm{H}}=C_{\mathrm{A}}-C_{\mathrm{B}}-\left[\mathrm{H}^{+}\right]_{\text {meas }}+\left[\mathrm{OH}^{-}\right]_{\text {meas }}$,

where $C_{\mathrm{A}}$ and $C_{\mathrm{B}}$ are the concentrations of acid and base added to the suspension, respectively, and $\left(C_{\mathrm{A}}-C_{\mathrm{B}}\right)$ corresponds to TOTH (the total proton concentration in the system) $(\mathrm{mol} / \mathrm{L})$.

It is well known that aluminum (hydr)oxides can dissolve in both acidic and alkaline $\mathrm{pH}$ regions. The dissolution depends on equilibrium time and $\mathrm{pH}$; the concentration of dissolved aluminum $(\mathrm{mol} / \mathrm{L})$ can be expressed as

$\left[\mathrm{Al}_{\mathrm{dis}}\right]_{\mathrm{tot}}=-\int_{0}^{t} \gamma_{\mathrm{H}}(\mathrm{pH}) \mathrm{d} t$,

where $\gamma_{\mathrm{H}}(\mathrm{pH})$ is the dissolution rate (in moles per second) [39]. According to the results of batch experiments (Fig. 4) in $5 \mathrm{~h}$ equilibration time and $\mathrm{pH}$ domain (4-10), the dissolution of samples A, B, and C is limited.

From the titration data, the unprocessed charging curves can be represented as $\mathrm{pH}$ versus TOTH. Fig. 5 displays three different sets of experiments at three ionic strengths of three samples.

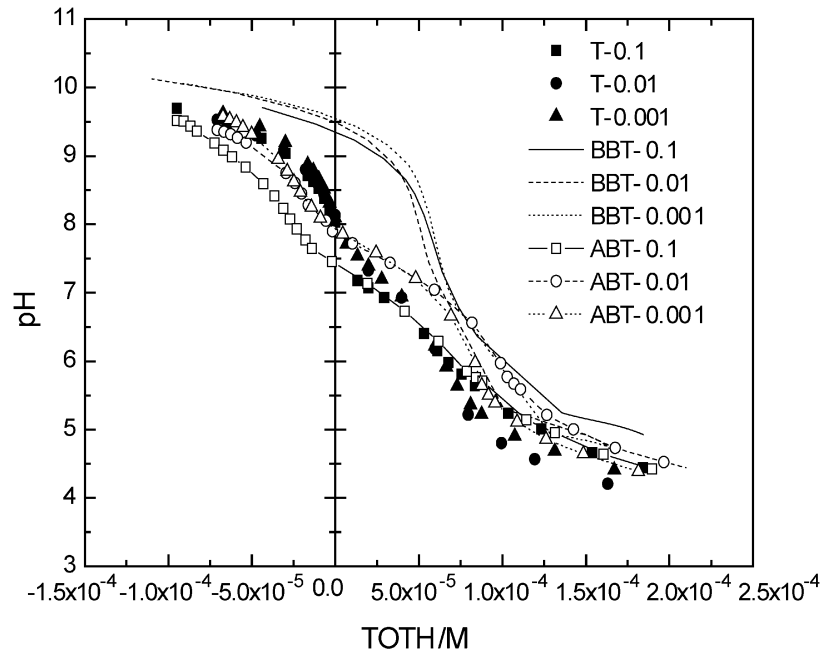

(a)

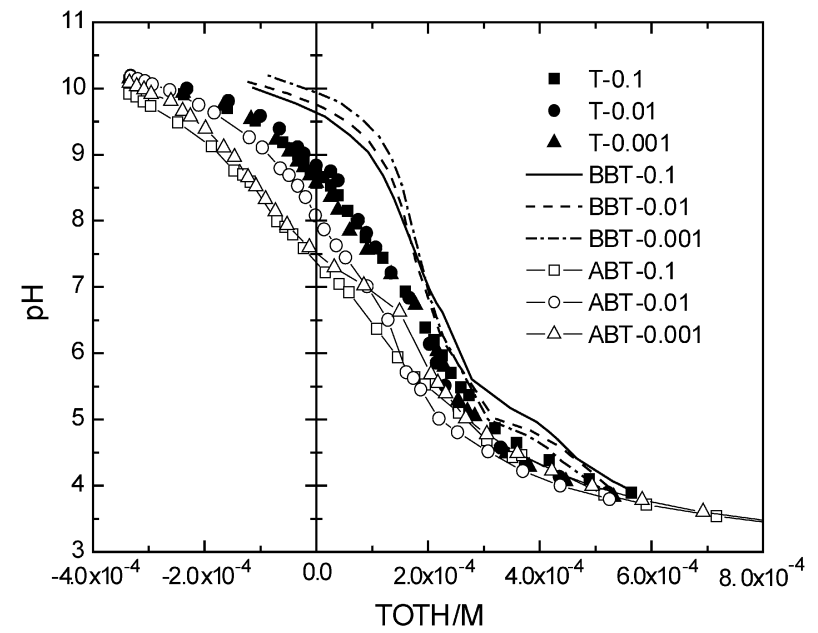

(b)

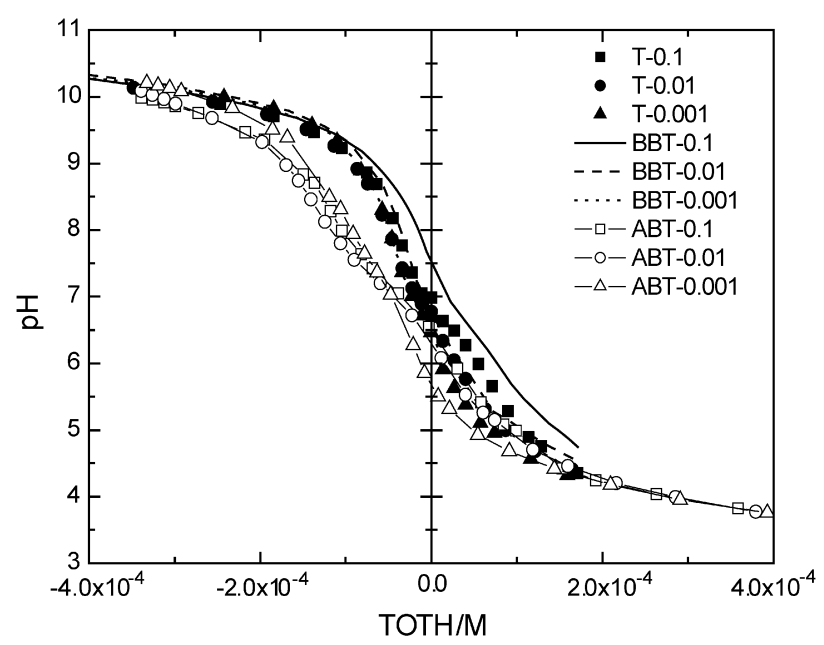

(c)

Fig. 5. Raw titration curves of three samples: (a) A, (b) B, and (c) C. T-sets: two-side titration, BBT-sets: base back-titration, and ABT-sets: acid backtitration.

A significant difference can be observed between the acid and base addition curves, which generate a hysteresis effect. For samples A and B, the BBT set titrations are more different from the others, and for sample $\mathrm{C}$, it seems that the difference is 


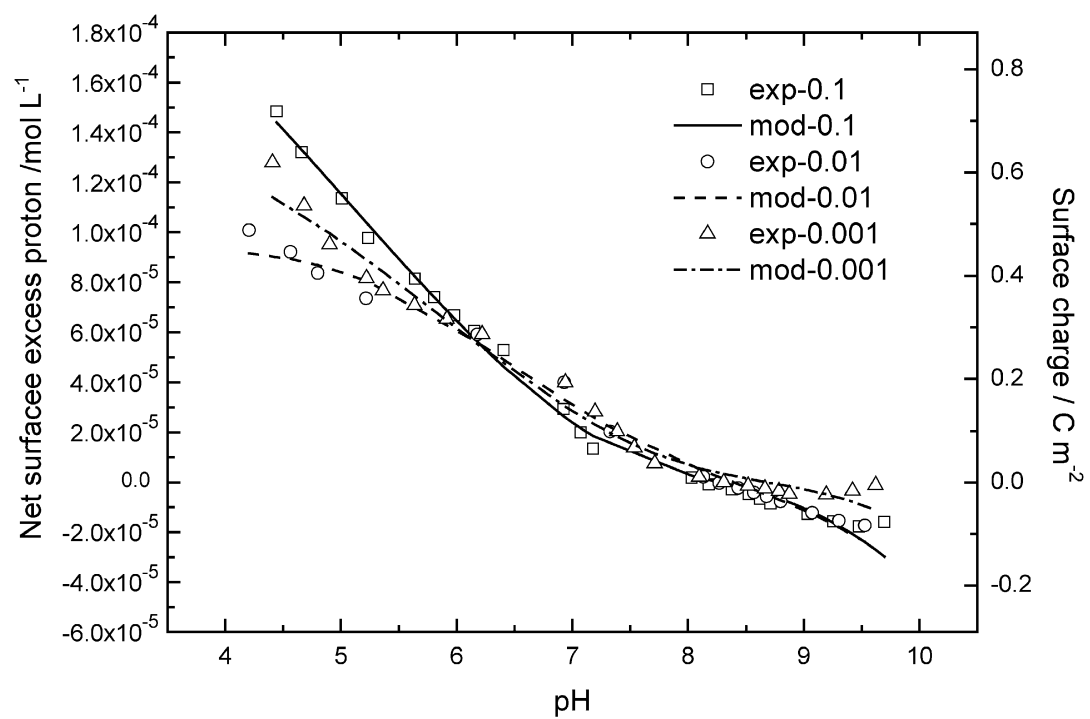

(a)

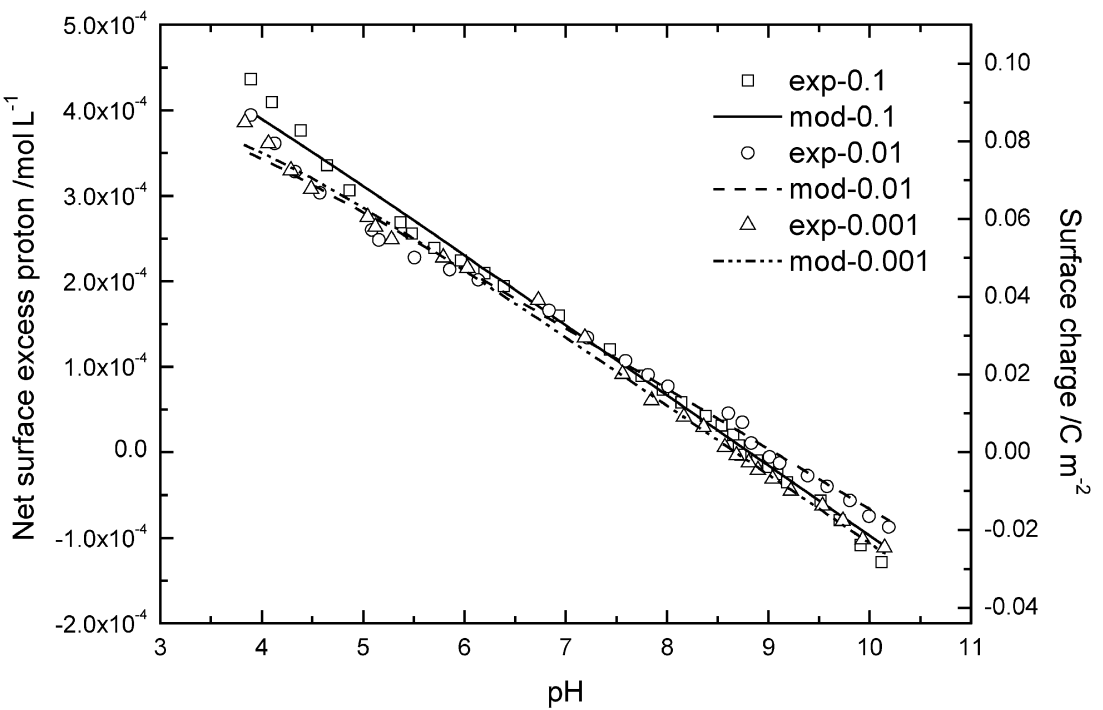

(b)

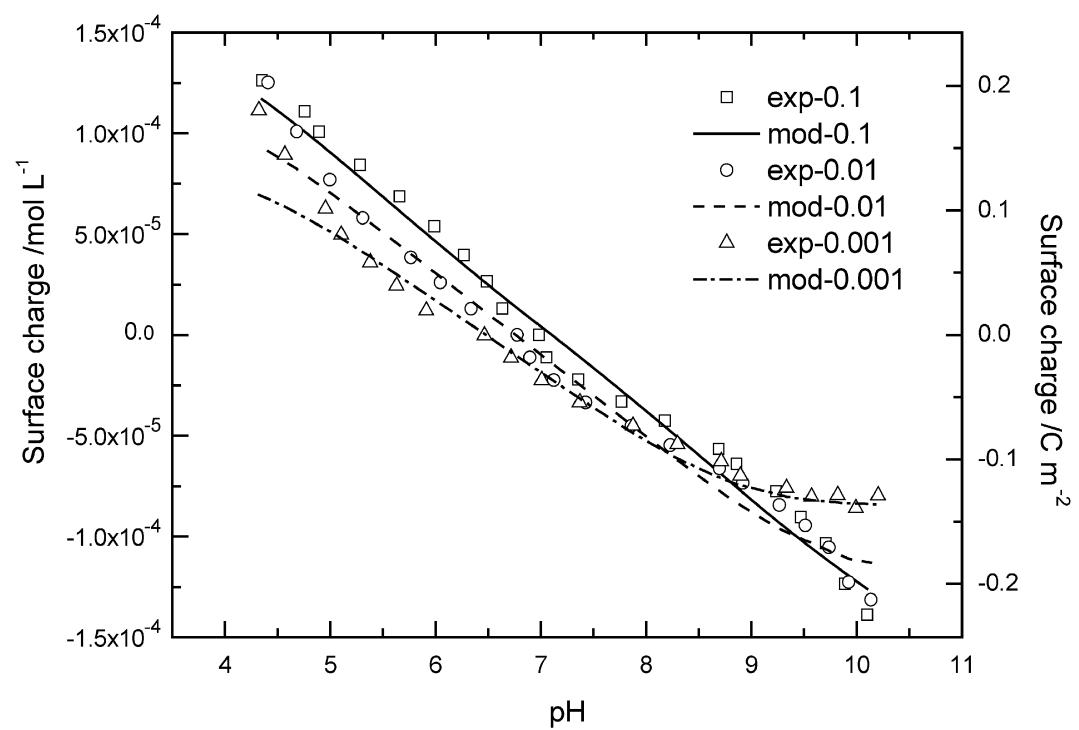

(c)

Fig. 6. Experimental net proton consumption from the two-side titrations for samples and fitted with 2pK-CCM: (a) sample A, (b) sample B, and (c) sample C. (Open points-titration data; lines—-model results.) 
Table 2

Literature-reported surface complexation models and relevant $\mathrm{p} K$ values for aluminum (hydr)oxides

\begin{tabular}{|c|c|c|c|c|}
\hline Sample description & Titration condition & Electrolyte & Model* $^{*}$ and $\mathrm{p} K$ values & Ref. \\
\hline $\begin{array}{l}\text { Gibbsite, from } \\
\mathrm{AlCl}_{3}+\mathrm{NaOH} \\
(\mathrm{pH} 4.6)\end{array}$ & $\begin{array}{l}\text { Sample aging } 9 \text { months } \\
\text { Slow titration: titration interval } 8-14 \mathrm{~h} \\
\text { Rapid titration: titration interval } 2 \mathrm{~min}\end{array}$ & $\begin{array}{l}\mathrm{NaCl} \\
0.1 \mathrm{M} \\
0.02 \mathrm{M}\end{array}$ & $\begin{array}{l}(\text { MUSIC-TPM }) \\
\text { PZNPC }(\text { cip })=9.0 \pm 0.2 \\
\mathrm{IEP}=10.0 \pm 0.1 \\
\mathrm{p} K_{1}=\mathrm{IEP}=10, \log K_{1-\mathrm{Na} / \mathrm{Cl}=0.1} \\
\mathrm{p} K_{2, \mathrm{Cl}}=8.49 \pm 0.1, \mathrm{p} K_{2, \mathrm{Na}}=9.62 \pm 0.1\end{array}$ & {$[42]$} \\
\hline $\begin{array}{l}\text { Gibbsite, from } \\
\mathrm{AlCl}_{3}+\mathrm{NaOH} \\
(\mathrm{pH} 4.5)\end{array}$ & $\begin{array}{l}\text { Adjust } \mathrm{pH} \text { to } 6-7 \text { overnight } \\
\text { Rapid titration: titration interval } 2 \mathrm{~min}\end{array}$ & $\begin{array}{l}\mathrm{NaNO}_{3} \\
0.005 \mathrm{M} \\
0.1 \mathrm{M}\end{array}$ & $\begin{array}{l}(\text { MUSIC-BSM) } \\
\log K_{1,2}=10(9.9) \\
\log K_{2,1}=11.9, \log K_{2,2}=0 \\
\log K_{\mathrm{Na}}=\log K_{\mathrm{NO}_{3}}=0.1, C=0.8-1.4 \mathrm{C} / \mathrm{m}^{2}\end{array}$ & {$[30]$} \\
\hline \multirow[t]{2}{*}{ Gibbsite, Alcoa } & $\begin{array}{l}\text { Equilibrating in electrolyte } \\
24 \mathrm{~h} \text { before titration } \\
50 \mu \mathrm{L} \text { acid or base in each addition } \\
\text { Titration rate was not given }\end{array}$ & $\begin{array}{l}\mathrm{NaNO}_{3} \\
0.1-0.001 \mathrm{M}\end{array}$ & $\begin{array}{l}(1 \mathrm{p} K \text {-BSM }) \\
\log K_{1}=8.7 \\
\log K_{\mathrm{Na}}=-0.304, \log K_{\mathrm{NO}_{3}}=7.974 \\
C_{1}=2.58 \mathrm{~F} / \mathrm{m}^{2}, C_{2}=5 \mathrm{~F} / \mathrm{m}^{2}\end{array}$ & {$[43]$} \\
\hline & $\begin{array}{l}\text { Adjust } \mathrm{pH} \text { to } 6 \text { for } 2 \mathrm{~h} \text { before titration } \\
50 \mu \mathrm{L} \mathrm{HNO}_{3} \text { addition each time } \\
\text { Titration rate was not given }\end{array}$ & $\mathrm{NaCl}$ & $\begin{array}{l}(1 \mathrm{p} K \text {-BSM }) \\
\log K_{1}=8.35, \log K_{\mathrm{Na}}=-0.304 \\
\log K_{\mathrm{Cl}}=7.761\end{array}$ & {$[44]$} \\
\hline $\begin{array}{l}\text { Gibbsite ( } 10 \% \text { Bayerite), } \\
\text { from } \mathrm{NaAlO}_{2} \text { aging } \\
\text { and acid rinsing }\end{array}$ & $\begin{array}{l}\text { Equilibrating in electrolyte } \\
30 \text { min before titration } \\
\text { Titration interval } 10 \mathrm{~min}\end{array}$ & $\begin{array}{l}\mathrm{NaNO}_{3} \\
0.1-0.001 \mathrm{M}\end{array}$ & $\begin{array}{l}\mathrm{pH}_{0} 6.84-9.22(0.01 \mathrm{M}) \\
7.2-9.14(0.1 \mathrm{M}) \\
\text { Modified MUSIC model: } \\
\log K_{\mathrm{AlOH}}=7.9-9.9, \log K_{\mathrm{Al}_{2} \mathrm{OH}}=2-4\end{array}$ & [26] \\
\hline $\begin{array}{l}\gamma-\mathrm{Al}_{2} \mathrm{O}_{3}, \text { from } \\
\mathrm{AlCl}_{3}+\mathrm{H}_{2} \mathrm{O} \text { (Alon) }\end{array}$ & $\begin{array}{l}\text { Rinsing with base solution and } \\
\text { aging over } 2 \text { weeks before titration } \\
\text { Titration interval } 2 \mathrm{~min}\end{array}$ & $\begin{array}{l}\mathrm{NaCl} \\
(0.1 \mathrm{M})\end{array}$ & $\begin{array}{l}\mathrm{p} K_{\mathrm{a} 1}=7.70, \mathrm{p} K_{\mathrm{a} 2}=9.30 \\
N_{\mathrm{s}}=0.625 \text { sites } / \mathrm{nm}^{2} \\
\mathrm{p} K_{\mathrm{a} 1}=5.7, \mathrm{p} K_{\mathrm{a} 2}=11.5 \\
\mathrm{p} K_{\mathrm{C}}=9.2(?), \mathrm{p}^{*} K_{\mathrm{A}}=7.9(?) \\
\left(\log K_{\mathrm{C}}=2.3, \log K_{\mathrm{A}}=2.2\right) \\
C_{1}=100-120 \mu \mathrm{F} / \mathrm{cm}^{2}\end{array}$ & $\begin{array}{l}{[7]} \\
{[45]}\end{array}$ \\
\hline$\gamma-\mathrm{Al}_{2} \mathrm{O}_{3}$, Alon & $\begin{array}{l}\text { Adding excess base back titration } \\
\text { for supernatants } \\
\text { Titration rate not given }\end{array}$ & $\begin{array}{l}\mathrm{NaClO}_{4} \\
(0.1 \mathrm{M})\end{array}$ & $\begin{array}{l}\mathrm{PZC}=8.3(3.75 \mathrm{~g} / \mathrm{L})=8.0(2.16 \mathrm{~g} / \mathrm{L}) \\
\mathrm{p} K_{\mathrm{a} 1}=7.2, \mathrm{p} K_{\mathrm{a} 2}=9.5\end{array}$ & [8] \\
\hline$\gamma-\mathrm{Al}_{2} \mathrm{O}_{3}$ & $\begin{array}{l}\text { Rinsing with } \mathrm{H}_{2} \mathrm{O} \text { and drying } \\
\text { at room temperature } \\
\text { Titration rate not given }\end{array}$ & $\mathrm{NaCl}$ & $\begin{array}{l}\mathrm{p} K_{\mathrm{a} 1}=4.9 \pm 0.5, \mathrm{p} K_{\mathrm{a} 2}=11.3 \pm 0.5 \\
\mathrm{p} K_{\mathrm{Na}}=8.6 \pm 0.1, \mathrm{p} K_{\mathrm{Cl}}=7.5 \pm 0.1\end{array}$ & [46] \\
\hline $\begin{array}{l}\delta-\mathrm{Al}_{2} \mathrm{O}_{3}, \text { from Degussa, } \\
\text { alumina } \mathrm{C} \\
1000^{\circ} \mathrm{C} \text { heat treatment }\end{array}$ & $\begin{array}{l}\text { Equilibrating in electrolyte } \\
\text { solution } 1 \mathrm{~h} \text { before titration } \\
\text { Titration interval } 2-5 \mathrm{~min}\end{array}$ & $\begin{array}{l}\mathrm{KCl} \\
(0.5-0.005 \mathrm{M}) \\
\mathrm{KNO}_{3} \\
(0.5-0.005 \mathrm{M})\end{array}$ & $\begin{array}{l}\mathrm{p} K_{\mathrm{a} 1}=5.8 \pm 0.2, \mathrm{p} K_{\mathrm{a} 2}=10.2 \pm 0.2 \\
2 \mathrm{p} K-\mathrm{CCM}:\left(C=1.2 \mathrm{~F} / \mathrm{m}^{2}\right) \\
\mathrm{p} K_{\mathrm{a} 1}=7.07 \pm 0.51, \mathrm{p} K_{\mathrm{a} 2}=9.10 \pm 0.31 \\
2 \mathrm{p} K-\mathrm{TLM}:\left(C_{1}=1.2-1.6, C_{2}=0.2 \mathrm{~F} / \mathrm{m}^{2}\right) \\
\mathrm{p} K_{\mathrm{a} 1}=7.23, \mathrm{p} K_{\mathrm{a} 2}=8.93 \\
\log K_{\mathrm{A}}=8.46 \pm 0.31, \log K_{\mathrm{C}}=-7.72 \pm 0.57\end{array}$ & {$[15]$} \\
\hline $\begin{array}{l}\gamma-\mathrm{Al}_{2} \mathrm{O}_{3}, \text { from Degussa, } \\
\text { alumina } \mathrm{C}\end{array}$ & $\begin{array}{l}\text { Without any pretreatment } \\
\text { Titration rate not given }\end{array}$ & $\begin{array}{l}\mathrm{NaClO}_{4} \\
(1.0 \mathrm{M})\end{array}$ & $\begin{array}{l}\mathrm{p} K_{\mathrm{a} 1}=4.45, \mathrm{p} K_{\mathrm{a} 2}=8.45 \\
N_{\mathrm{s}}=9.5 \times 10^{-6} \mathrm{~mol} / \mathrm{m}^{2}=5.7 \text { sites } / \mathrm{nm}^{2} \\
C=2.5 \mathrm{~F} / \mathrm{m}^{2}\end{array}$ & [9] \\
\hline $\begin{array}{l}\gamma-\mathrm{Al}_{2} \mathrm{O}_{3}, \text { from Degussa, } \\
\text { alumina } \mathrm{C}\end{array}$ & $\begin{array}{l}\text { Rinsing with } \mathrm{H}_{2} \mathrm{O} \\
\text { Titration rate not given }\end{array}$ & $\begin{array}{l}\mathrm{NaNO}_{3} \\
0.001 \mathrm{M} \\
0.1 \mathrm{M} \\
0.5 \mathrm{M}\end{array}$ & $\begin{array}{l}2 \mathrm{p} K \text {-CCM: }\left(C_{1}=1.06 \mathrm{~F} / \mathrm{m}^{2}\right) \\
\mathrm{p} K_{\mathrm{a} 1}=6.7, \mathrm{p} K_{\mathrm{a} 2}=9.0, N_{\mathrm{S}}=1.4 \text { sites } / \mathrm{nm}^{2} \\
2 \mathrm{p} K-\mathrm{DLM}: \\
\mathrm{p} K_{\mathrm{a} 1}=7.3, \mathrm{p} K_{\mathrm{a} 2}=8.6, N_{\mathrm{S}}=0.9 \text { sites } / \mathrm{nm}^{2} \\
\text { Modified stern: }\left(C_{1}=2.4 \mathrm{~F} / \mathrm{m}^{2}\right) \\
\mathrm{p} K_{\mathrm{a} 1}=7.3, \mathrm{p} K_{\mathrm{a} 2}=8.5, N_{\mathrm{S}}=0.9 \text { sites } / \mathrm{nm}^{2} \\
2 \mathrm{p} K-\mathrm{TLM}:\left(C_{1}=1.2, C_{2}=0.2 \mathrm{~F} / \mathrm{m}^{2}\right) \\
\mathrm{p} K_{\mathrm{a} 1}=7.0, \mathrm{p} K_{\mathrm{a} 2}=8.8, N_{\mathrm{s}}=0.9 \text { sites } / \mathrm{nm}^{2} \\
\log { }^{*} K_{\mathrm{Na}}=-8.3, \log * K_{\mathrm{NO}_{3}}=8.3\end{array}$ & {$[47]$} \\
\hline
\end{tabular}

reduced. Jodin et al. [26] also observed these hysteresis phenomena and explained them by the effect of the ionic strength and the solids not being at their point of zero charge at the end of the dialysis process. Gaboriaud and Ehrhardt [27] thought this hysteresis effect originates from carbonate contamination. And Kosmulski [40] attributed the behavior to the disparity of fast reaction and slow $\mathrm{pH}$ drift. By making a comparison with the blank electrolyte titration data, we can exclude the 
Table 3

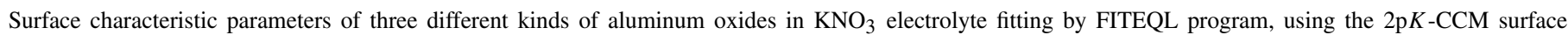
complexation model

\begin{tabular}{|c|c|c|c|c|c|c|c|}
\hline & $I(\mathrm{M})$ & $C_{\text {ap }}\left(\mathrm{F} / \mathrm{m}^{2}\right)$ & $N_{\mathrm{s}}\left(\right.$ sites $\left./ \mathrm{nm}^{2}\right)$ & $\mathrm{p} K_{\mathrm{a} 1}$ & $\mathrm{p} K_{\mathrm{a} 2}$ & $V_{y}$ & PZNPC \\
\hline \multirow[t]{4}{*}{ A } & 0.1 & 7.1 & 6.78 & 6.35 & 10.17 & 5.30 & 8.26 \\
\hline & 0.01 & 5.8 & 2.83 & 7.14 & 9.63 & 6.12 & 8.39 \\
\hline & 0.001 & 5.3 & 4.16 & 6.86 & 10.49 & 11.73 & 8.68 \\
\hline & & & & $6.78 \pm 0.40$ & $10.10 \pm 0.43$ & & $8.44 \pm 0.21$ \\
\hline \multirow[t]{4}{*}{ B } & 0.1 & 3.21 & 6.63 & 8.18 & 9.45 & 11.83 & 8.81 \\
\hline & 0.01 & 2.71 & 5.12 & 8.56 & 9.56 & 18.74 & 9.06 \\
\hline & 0.001 & 2.87 & 4.72 & 8.68 & 8.67 & 9.06 & 8.68 \\
\hline & & & & $8.50 \pm 0.26$ & $9.20 \pm 0.49$ & & $8.85 \pm 0.19$ \\
\hline \multirow[t]{4}{*}{$\mathrm{C}$} & 0.1 & 2.2 & 1.57 & 6.29 & 7.91 & 27.94 & 7.10 \\
\hline & 0.01 & 2.22 & 1.19 & 6.03 & 7.42 & 28.33 & 6.73 \\
\hline & 0.001 & 2.25 & 0.85 & 5.78 & 7.08 & 35.31 & 6.43 \\
\hline & & & & $6.03 \pm 0.25$ & $7.47 \pm 0.42$ & & $6.75 \pm 0.34$ \\
\hline
\end{tabular}

Note. $\mathrm{PZNPC}=\left(\mathrm{p} K_{\mathrm{a} 1}+\mathrm{p} K_{\mathrm{a} 2}\right) / 2$.

interference of electrode signal shift. The irreversibility of the titration curves may be caused by dissolved aluminum species during the long-time titration procedures. The solubility curves in Fig. 4 indicate some dissolution at extreme $\mathrm{pH}$ values. In both the acidic and alkaline back titration processes, these dissolved solution species together with mineral surfaces possibly react with either acid or base leading to the irreversibility. In sample $\mathrm{C}$ ( $\alpha$-alumina), the hysteresis effect seems to be reduced. Thus some differences in the interface structure and particle size might be considered, which could slow down the diffusion of aqueous species toward the solid surface and make the $\mathrm{pH}$ drift to become faster than the slow surface reactions. As described above, for the hexagonal prisms morphology of samples $\mathrm{A}$ and $\mathrm{B}$, two types of crystal faces can be found. These two faces with different reactive sites [25] may have different kinetics with respect to the back-titration processes. For $\alpha$-alumina, at which the interlayer coordination between aluminum and oxygen is well established in all $(a, b$, and $c)$ directions, the surface properties of different faces may be expected similarly [36].

As shown in Fig. 6, for the $\mathrm{pH}$ range investigated, the surface charge is usually larger at higher ionic strength. This is because the increased electrolyte concentration pressed the double layer thickness and reduced the electrostatic repulsion on the surface.

From Fig. 6, the point of zero proton charge $\left(Q_{\mathrm{H}}=0\right)$ at different ionic strength has marginal differences. Sample A is at $\mathrm{pH}(8.1,8.2,8.3)$, sample $\mathrm{B}$ is at $\mathrm{pH}(8.8,8.9,8.7)$, and sample $\mathrm{C}$ is at $\mathrm{pH}(7.0,6.8,6.5)$ in $(0.1,0.01,0.001 \mathrm{M}) \mathrm{KNO}_{3}$, respectively. The common intersection point (cip) of curves for samples A, B, and C is $6.2 \pm 0.2,7.0 \pm 0.2$, and $8.9 \pm 0.2$, respectively.

Although the surface complexation of aluminum (hydr)oxides has been extensively studied, the reported constants are rarely the same, mainly due to the differences in sample preparations, experimental conditions, hydration times, etc. Some published data are listed in Table 2. Obviously, the published data vary considerably even for the same mineral.
There are several approaches to modeling the surface charge curves using surface site models. A simplified approach assumes that the surface is homogeneous and all surface groups can be represented as $\mathrm{SOH}$, and the charge occurs via a two-step $(2 \mathrm{p} K)$ protonation reaction $[5,41]$. Then the surface reaction could be expressed as

$$
\begin{aligned}
& \equiv \mathrm{AlOH}_{2}^{+} \leftrightarrow \equiv \mathrm{AlOH}+\mathrm{H}^{+}, \quad \mathrm{p} K_{\mathrm{a} 1}, \\
& \equiv \mathrm{AlOH} \leftrightarrow \equiv \mathrm{AlO}^{-}+\mathrm{H}^{+}, \quad \mathrm{p} K_{\mathrm{a} 2} .
\end{aligned}
$$

From Fig. 6 it is clear that the classical 2pK-CCM approach leads to a good description of the charging behavior of all three samples. The theoretical data fit well with the experimental results. The protonation and the site density were optimized by adjusting the capacitance of the interface, and the fitting parameters are summarized in Table 3. Since the surface hydration tends to develop Brønsted acid sites, the Brønsted acid/base acidity of surface hydroxyls can be evaluated by $\mathrm{p} K_{\mathrm{a}}$ values. The surface acidity can be interpreted by the $\mathrm{p} K_{\mathrm{a} 1}$ value of the surface reaction. The $\mathrm{p} K_{\mathrm{a} 1}$ values of three typical aluminas are $6.03 \pm 0.25$ for $\alpha-\mathrm{Al}_{2} \mathrm{O}_{3}, 6.78 \pm 0.4$ for $\gamma-\mathrm{Al}(\mathrm{OH})_{3}$, and $8.50 \pm 0.29$ for $\gamma-\mathrm{Al}_{2} \mathrm{O}_{3}$, respectively, and consequently the order of the surface acidity of these three samples is $\alpha-\mathrm{Al}_{2} \mathrm{O}_{3}>$ $\gamma-\mathrm{Al}(\mathrm{OH})_{3}>\gamma-\mathrm{Al}_{2} \mathrm{O}_{3}$.

The difference in surface acidity reflects the difference of the surface chemical composition of various alumina minerals. It is reasonable that different aluminol groups $(\equiv \mathrm{AlOH}$, $\left.\equiv \mathrm{Al}_{2} \mathrm{OH}, \equiv \mathrm{Al}(\mathrm{OH})_{2}\right)$ may exist at the hydrated alumina surfaces. The aluminum ions affect the acidity and the oxide ions contribute to the alkalinity; i.e., the more aluminum at the surfaces, the stronger the surface acidity. $\alpha-\mathrm{Al}_{2} \mathrm{O}_{3}$ represents the end structure of the alumina dehydration: the surfaces may transfer from gibbsite to boehmite and then to $\gamma$-alumina and finally to $\alpha$-alumina with the progressing of dehydration. The surface of alumina (hydr)oxide from gibbsite to boehmite and then to the $\gamma$-alumina dehydration/hydration process may be 
visualized as Eq. (5).

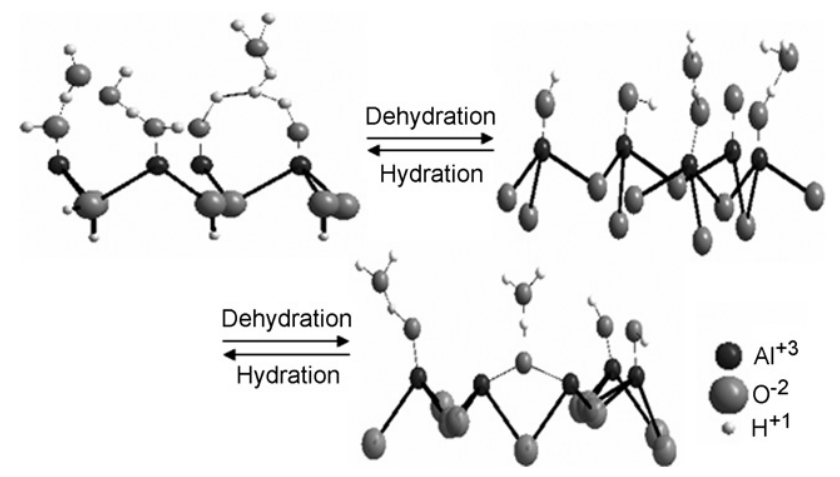

The surface of gibbsite during dehydration may involve the following steps: first the physically adsorbed water is released and then the chemically adsorbed water. After that the surface oxygen ions' coordination environment of $\mathrm{Al}$ ions changed into $\left(\mathrm{Al}, \mathrm{O}_{6}\right)$ octahedra and tended to form oxygen bridges between surface aluminum ions, leading to higher acidity at the surface binding sites. The three surface states of alumina, i.e., physically adsorbed water, chemically adsorbed water, and oxygen bridges at the surface of aluminum (hydr)oxide may be depicted as

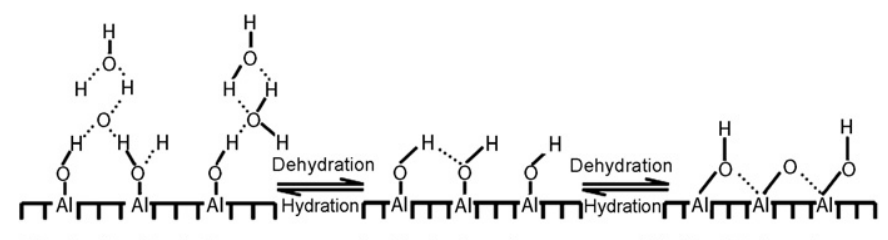

Physically adsorbed water $\quad$ Surface hydroxyl groups $\quad \mathrm{O}$ bridge-Hydroxyl groups

The surface hydration of $\alpha-\mathrm{Al}_{2} \mathrm{O}_{3}$ may be regarded as a reversible process of gibbsite dehydration. At the last stage of the hydration the gibbsite surface may form, and that is the case reported. From the comparison of three typical aluminum (hydr)oxides we can understand that the fundamental differences of surface morphology can be attributed to the type and combination of singly or doubly bonded hydroxyl with aluminum ions. The more aluminum-bonded hydroxyl, the stronger the surface acidity, and the more oxygen involved in the surface bonding, the stronger the surface alkalinity.

\section{Conclusions}

The following conclusions can be drawn from our studies:

- Within the framework of the constant capacitance surface complexation model, $2 \mathrm{p} K$ models can give a good description of the experimental data of gibbsite, $\gamma$-alumina, and $\alpha$-alumina, with different ionic strengths. The $\mathrm{p} K_{1}$ and $\mathrm{p} K_{2}$ for gibbsite, $\gamma$-alumina, and $\alpha$-alumina are $6.78 \pm 0.4$ and $10.10 \pm 0.43 ; 8.50 \pm 0.29$ and $9.20 \pm 0.52$; and $6.03 \pm 0.25$ and $7.47 \pm 0.42$, respectively, depending on ionic strength. The surface acidity of these minerals follows the order $\alpha-\mathrm{Al}_{2} \mathrm{O}_{3}>\gamma-\mathrm{Al}(\mathrm{OH})_{3}>\gamma-\mathrm{Al}_{2} \mathrm{O}_{3}$.
- The dehydration of gibbsite can be regarded as a reversible process of hydration of $\alpha$-alumina; $\gamma$-alumina and boehmite are the intermediate products of gibbsite dehydration or $\alpha$-alumina hydration.

- The fundamental differences of the surface morphology of aluminum (hydr)oxides are the proportion of singly and doubly coordinated aluminum-oxygen bonding; the more aluminum in the bonding the greater the surface acidity.

\section{Acknowledgments}

Financial support from the Chinese Natural Science Foundation (Nos. 20537020, 20677022, and 50621804) and Jinan University (B0400) is gratefully acknowledged.

\section{References}

[1] B. Kasprzyk-Hordern, Adv. Colloid Interface Sci. 110 (2004) 19.

[2] C. Morterra, G. Magnacca, Catal. Today 27 (1996) 497.

[3] D.A. Dzombak, F.M.M. Morel, Surface Complexation Modeling: Hydrous Ferric Oxide, Wiley, New York, 1990.

[4] J.J. Morgan, W. Stumm, J. Colloid Sci. 19 (1964) 347.

[5] G.A. Parks, P.L. de Bruyn, J. Phys. Chem. 66 (1962) 967.

[6] J.A. Yopps, D.W. Fuerstenau, J. Colloid Sci. 19 (1964) 61.

[7] C.P. Huang, W. Stumm, J. Colloid Interface Sci. 43 (1973) 409.

[8] H. Hohl, W. Stumm, J. Colloid Interface Sci. 55 (1976) 281.

[9] P.V. Brady, Geochim. Cosmochim. Acta 58 (1994) 1213.

[10] Z.X. Sun, F.W. Su, W. Forsling, P.O. Samskog, J. Colloid Interface Sci. 197 (1998) 151.

[11] J.F. Boily, J. Lutzenkirchen, O. Balmes, J. Beattie, S. Sjoberg, Colloids Surf. A 179 (2001) 11.

[12] G. Lefevre, M. Duc, P. Lepeut, R. Caplain, M. Fedoroff, Langmuir 18 (2002) 7530.

[13] E. Laiti, P. Persson, L.A. Ohman, Langmuir 14 (1998) 825.

[14] C. Dyer, P.J. Hendra, W. Forsling, M. Ranheimer, Spectrochim. Acta A 49 (1993) 691.

[15] E. Tombacz, M. Szekeres, Langmuir 17 (2001) 1411.

[16] T.W. Healy, L.R. White, Adv. Colloid Interface Sci. 9 (1978) 303.

[17] P.W. Schindler, B. Furst, R. Dick, P.U. Wolf, J. Colloid Interface Sci. 55 (1976) 469.

[18] Y. Zhang, L. Charlet, P.W. Schindler, Colloids Surf. A 63 (1992) 259.

[19] R. Kummert, W. Stumm, J. Colloid Interface Sci. 75 (1980) 373.

[20] J.A. Davis, J.O. Leckie, J. Colloid Interface Sci. 67 (1978) 90.

[21] J.A. Davis, J.O. Leckie, J. Colloid Interface Sci. 74 (1980) 32.

[22] K.F. Hayes, G. Redden, W. Ela, J.O. Leckie, J. Colloid Interface Sci. 142 (1990) 448.

[23] G.H. Bolt, W.H. van Riemsdijk, in: G.H. Bolt (Ed.), Soil Chemistry: B. Physico-Chemical Models, Elsevier, Amsterdam, 1982, p. 459.

[24] T. Hiemstra, W.H. van Riemsdijk, G.H. Bolt, J. Colloid Interface Sci. 133 (1989) 91.

[25] T. Hiemstra, J.C.M. de Wit, W.H. van Riemsdijk, J. Colloid Interface Sci. 133 (1989) 105

[26] M.C. Jodin, F. Gaboriaud, B. Humnert, J. Colloid Interface Sci. 287 (2005) 581.

[27] F. Gaboriaud, J.J. Ehrhardt, Geochim. Cosmochim. Acta 67 (2003) 967.

[28] R. Weerasooriya, H.K.D.K. Wijesekara, A. Bandara, Colloid Surf. A 207 (2002) 13.

[29] W.H. Rowlands, R.W. O'Brien, R.J. Hunter, V. Patrick, J. Colloid Interface Sci. 188 (1997) 325.

[30] T. Heimstra, H. Yong, W.H. van Riemsdijk, Langmuir 15 (1999) 5942.

[31] P.J. Eng, T.P. Trainor, G.E. Brown Jr., G.A. Waychunas, M. Newville, S.R. Sutton, M.L. Rivers, Science 288 (2000) 102.

[32] A.L. Herbelin, J.C. Westall, FITEQL v4.0-A, computer program for determination of chemical equilibrium constants from experimental data, Oregon State University, 1999, Report 99-01. 
[33] P.S. Santos, H.S. Santos, S.P. Toledo, J. Mater. Res. 3 (2000) 104.

[34] J.T. Kloprogge, H.D. Ruan, R.L. Frost, J. Mater. Sci. 37 (2002) 1121.

[35] R.L. Frost, J.T. Kloprogge, S.C. Russell, J.L. Szetu, Appl. Spectrosc. 53 (1999) 423.

[36] S. Goldgerg, J.A. Davis, J.D. Hem, in: G. Sposito (Ed.), The Environmental Chemistry of Aluminum, CRC Press, New York, 1996, p. 272.

[37] K. Sohlberg, S.J. Pennycook, S.T. Pantelides, J. Am. Chem. Soc. 121 (1999) 7493.

[38] C.W. Yong, M.C. Warren, I.H. Hillier, D.J. Waughan, Phys. Chem. Miner. 30 (2003) 76.
[39] G. Lefevre, M. Duc, M. Fedoroff, J. Colloid Interface Sci. 269 (2004) 274.

[40] M. Kosmulski, J. Colloid Interface Sci. 253 (2002) 77.

[41] L.K. Koopal, Electrochim. Acta 41 (1996) 2293.

[42] J. Rosenqvist, P. Persson, S. Sjoberg, Langmuir 18 (2002) 4598.

[43] R. Weerasooriya, B. Dharmasena, D. Aluthpa, Colloids Surf. A 170 (2000) 65.

[44] R. Weerasooriya, Colloids Surf. A 189 (2001) 131.

[45] J.A. Davis, R.O. James, J.O. Leckie, J. Colloid Interface Sci. 63 (1978) 480.

[46] R. Sprycha, J. Colloid Interface Sci. 127 (1989) 1, 12.

[47] C.V. Toner, D.L. Sparks, Soil Sci. Soc. Am. J. 59 (1995) 395. 